\title{
Organ dysfunction other than central nervous system in perinatal asphyxia
}

\author{
Vivek Singh ${ }^{1}$, COL D.Y. Shrikhande ${ }^{2}$, ${ }^{*}$ ohit Vohra ${ }^{1}$, Amit Garg ${ }^{2}$ \\ Sri Lanka Journal of Child Health, 2018; 47(2): 141-145
}

\begin{abstract}
Introduction: Significant asphyxial insult to the fetus is likely to compromise a number of different organ systems of which the brain, kidneys and myocardium are particularly vulnerable, though bowel, endocrine and pulmonary complications may also occur. However much emphasis is given to central nervous system (CNS) dysfunction while other organs take a backseat.
\end{abstract}

Objectives: To evaluate the frequency of organ dysfunction other than CNS in perinatal asphyxia and to correlate the organ dysfunction with immediate mortality.

Method: A prospective observational study was done in all asphyxiated newborns, delivered at Pravara Institute of Medical Sciences, Loni, from September 2013 to August 2015. Neonates born before 37 weeks of gestation, or born outside the hospital or with congenital anomalies or with early onset sepsis were excluded from the study. Prior approval was obtained from the institutional ethics committee. A detailed history was taken and examination performed on admission to the neonatal intensive care unit (NICU). The clinical course was followed up to 14 days of birth. Data obtained was recorded. Data analysis was done by descriptive statistics as mean, SD, median, range and percentage. Comparison was done by applying Chi-square test. Significance was assessed at 5\% $(\mathrm{p}<0.05)$.

Results: During the study period 152 asphyxiated babies, fulfilling the preformed inclusion criteria were admitted in the NICU. The common modes of delivery were normal vaginal $(55.2 \%)$ and caesarean section (38\%). Meconium stained amniotic fluid $(35.5 \%)$ was the most common perinatal risk factor followed by prolonged second stage of labour $(23.7 \%)$. The renal system was involved in $64 \%$ cases, respiratory system in $45 \%$,

${ }^{1}$ Sir Ganga Ram Hospital, India, ${ }^{2}$ Pravara Institute
of Medical Sciences, India
*Correspondence: drrohitvohra87@gmail.com
(Received on 19 July 2017: Accepted after revision
on 18 August 2017)
The authors declare that there are no conflicts of
interest
Personal funding was used for the project.
Open Access Article published under the Creative

Commons Attribution CC-BY (cC) (i) cardiovascular system in 32\%, gastrointestinal system in $16 \%$, hepatic system in $05 \%$ and the haematological system in $03 \%$. There was an overall mortality rate of $37.5 \%$.

Conclusions: In the present study common organs of involvement other than the CNS were renal $(64 \%)$, respiratory $(45 \%)$, cardiovascular $(32 \%)$ and gastrointestinal $(16 \%)$. The overall mortality rate was $37.5 \%$. Deaths were higher when 3 or more organs were involved.

DOI: http://dx.doi.org/10.4038/sljch.v47i2.8480

(Key words: Neonates, birth asphyxia, organ dysfunction, mortality)

\section{Introduction}

Perinatal asphyxia remains an important cause of neonatal mortality, morbidity and late sequelae especially in a developing country like India. Initially, birth asphyxia was thought to result only in central nervous system (CNS) dysfunction and not much consideration was given to the involvement of other systems as a result of asphyxia. However, it is known now that a significant asphyxial insult to the fetus is likely to compromise a number of different organ systems of which the brain, kidneys and myocardium are particularly vulnerable, though bowel, endocrine and pulmonary complications may also occur ${ }^{1}$. Early recognition of infants with multisystem dysfunction after a perinatal asphyxial insult may be beneficial in the management of these infants and may have a bearing on their outcome.

\section{Objectives}

To evaluate the frequency of organ dysfunction other than CNS in perinatal asphyxia.

\section{Method}

A prospective observational hospital based study was done in all asphyxiated newborns, delivered at Pravara Institute of Medical Sciences, Loni, from September 2013 to August 2015, who had features of birth asphyxia with an Apgar score of $\leq 7$ at $5 \mathrm{~min}$, or/and umbilical cord arterial $\mathrm{pH}$ of $<7.2$ at birth, or/and required more than 1 minute of positive pressure ventilation before sustained respiration, or the need for mechanical ventilation at birth. Neonates born before 37 weeks of gestation, or born outside Pravara Institute of Medical Sciences, Loni or with congenital anomalies or with early onset sepsis were excluded 
from the study. Approval from the institutional ethics committee, letter number (PMT/PMIS/RC/2013/17) and written consent was taken from all parents before inclusion of their child in the study.

A detailed history was taken and examination performed at the time of admission to the neonatal intensive care unit (NICU). The clinical course was followed up to 14 days of birth. Data obtained were recorded. Natal history included the mode of delivery and indications for interventions, if any. Complications during and prior to labour were noted. All births were attended and resuscitated by paediatricians following the 2010 neonatal resuscitation protocol of the American Academy of Pediatrics ${ }^{2}$. Postnatal history included details regarding birth asphyxia, resuscitation measures and APGAR scores at 1 and 5 minutes. Gestational age was assessed based on mother's last menstrual period (LMP) and confirmed when necessary by early antenatal ultrasonography (USG). When the LMP was not available and antenatal USG was not done, gestational age was assessed by the Modified Ballard Scoring system ${ }^{3}$. All biochemical samples were taken on admission. Echocardiography was done at Department of Radiology at Pravara Institute of Medical Sciences, Loni. Daily follow-up of the patient was done and overall progress was monitored till discharge from NICU or death of the baby.

Blood urea, serum creatinine and urine output record (monitored using a plastic collection bag, Minicom) were done in all cases at the time of admission, at 72 hours of age and after one week. Acute renal failure was considered to be present if the urine output was less than $0.5 \mathrm{ml} / \mathrm{kg} /$ hour, or the blood urea was more than $40 \mathrm{mg} / \mathrm{dl}$, or the serum creatinine was more than $2 \mathrm{SD}$ above the mean value for gestational age which is more than $1.2 \mathrm{mg} / \mathrm{dl}$. For calculating creatinine clearance we used Schwatrz formula ${ }^{4}$, Creatinine clearance $=\mathrm{k} \mathrm{x}$ $\mathrm{L} / \mathrm{Pcr}$, where $\mathrm{L}$ is length or height of the child in $\mathrm{cm}, \mathrm{Pcr}$ is plasma creatinine in $\mathrm{mg} / \mathrm{dl}$ and $\mathrm{K}$ is age dependent constant (for preterm 0.33, term 0.45).

Respiratory system was assessed based on the presence of respiratory distress with need for oxygen supplementation for more than 24 hours and/or mechanical ventilation. Assessment of respiratory distress was done by Downes score. Chest x-ray was done in all infants needing oxygen supplementation. Each infant was examined for the presence of a heart murmur, dysrhythmias, cyanosis, increase in respiratory distress with systemic hypotension and signs of shock (hepatomegaly, abnormal peripheral pulses, reduced peripheral pulsation evident by prolonged CRT $>3 \mathrm{sec}$.) that required need of IV inotropes. A 12-lead electrocardiogram (ECG) was done in each asphyxiated neonate within 72 hours of life to look for transient myocardial ischaemia. Infants with grade 1 or 2 ECG changes of were considered to have mild, and those with grades 3 or 4 changes, severe myocardial ischaemia respectively. The grading was done as per criteria defined by Jedeikin et al. ${ }^{5}$. Creatinine kinase-MB isoenzyme levels were estimated at 8 hours and 24 hours of life in all neonates. A value of more than $92.6 \mathrm{U} / \mathrm{L}$ at 8 hours and $60 \mathrm{U} / \mathrm{L}$ at 24 hours were taken as high. In cases with persistent murmurs and other abnormal findings, an echocardiography was carried out.

Evaluation was done for the presence of gastrointestinal (GI) bleed, abdominal distension, and altered GI aspirate. Enteral feeding was started only after 24 hours after birth in all cases. Modified Bell's criteria were used for necrotizing enterocolitis. Criteria for liver impairment were aspartate transaminase (AST) $>100 \mathrm{U} / \mathrm{L}$, alanine transaminase $(\mathrm{ALT})>100 \mathrm{U} / \mathrm{L}$, prothrombin time $>20$ seconds, and/or international normalised ratio (INR) $>1.2$, measured on postnatal days 1,3 , and 10 in all asphyxiated babies. All infants had platelet counts done. Significant thrombocytopenia was considered to be present when the platelet count was less than $100,000 / \mathrm{cu} \mathrm{mm}$. Any evidence of bleeding tendencies like petechiae was noted during the hospital stay. All infants had daily random blood sugar (RBS) estimations. Hypoglycaemia was defined as RBS $<45 \mathrm{mg} \%$; hyponatremia as serum sodium $<130 \mathrm{mg} / \mathrm{L}$; hyperkalaemia as serum potassium $>5 \mathrm{meq} / \mathrm{L}$ and hypocalcaemia as serum calcium $<7.5 \mathrm{mg} \%$. For calculating plasma osmolarity we used the following equation: Calculated osmolarity $=2 \mathrm{Na}+$ Glucose + Urea (all in $\mathrm{mmol} / \mathrm{L}$ ). Routine investigations included haemoglobin $(\mathrm{Hb}) \%$, total leucocyte count, differential count, platelet count, sepsis screening (C-reactive protein, toxic granules and band cells), blood urea, serum creatinine, serum electrolytes $\left(\mathrm{Na}^{+}, \mathrm{K}^{+}, \mathrm{Ca}^{+}\right)$, blood culture and antibiotic sensitivity. Special investigation included x-rays (chest and abdomen), ECG, echocardiography and USG (abdomen and pelvis)

Data analysis was done by descriptive statistics as mean, SD, median, range and percentage. Comparison was done by applying Chi-square test. Significance was assessed at $5 \% \quad(\mathrm{p}<0.05)$. GraphPadInstat version 3.10 software was used for statistical analysis. Microsoft word and excel were used to generate graphs and tables

\section{Results}

Thirteen thousand four hundred and twenty three deliveries were conducted during the study period out of which 12,213 were live births. During this 
period 152 asphyxiated babies fulfilling the preformed inclusion criteria were admitted in NICU. Table 1 shows the gender distribution of the neonates with perinatal asphyxia. Table 2 shows the mode of delivery among case of perinatal asphyxia. Table 3 shows the perinatal risk factors in neonates with perinatal asphyxia.

Table 1: Gender-wise distribution of neonates in perinatal asphyxia

\begin{tabular}{|l|c|}
\hline \multicolumn{1}{|c|}{ Gender } & Number (\%) \\
\hline Male & $84(55.3)$ \\
\hline Female & $68(44.7)$ \\
\hline
\end{tabular}

Table 2: Mode of delivery in cases of perinatal asphyxia

\begin{tabular}{|l|c|}
\hline \multicolumn{1}{|c|}{ Mode of delivery } & Number (\%) \\
\hline Normal vaginal & $84(55.2)$ \\
\hline Ventouse & $07(04.9)$ \\
\hline Forceps & $03(02.0)$ \\
\hline Caesarean section (LSCS) & $58(38.0)$ \\
\hline Total & $152(100,0)$ \\
\hline
\end{tabular}

Table 3: Perinatal risk factors in perinatal asphyxia

\begin{tabular}{|c|c|}
\hline Risk Factor & No. (\%) \\
\hline Meconium stained amniotic fluid & $54(35.5)$ \\
\hline Prolonged second stage of labour & $36(23.7)$ \\
\hline $\begin{array}{l}\text { Pregnancy induced hypertension/ } \\
\text { eclampsia }\end{array}$ & $13(08.5)$ \\
\hline Cord prolapse & $10(07.7)$ \\
\hline Malpresentation & $08(05.2)$ \\
\hline Premature rupture of membrane & $07(04.5)$ \\
\hline Cord around neck & $05(03.2)$ \\
\hline Twin delivery & $03(01.8)$ \\
\hline Oligohydramnios & $03(01.8)$ \\
\hline Abruptio placentae & $03(01.8)$ \\
\hline Antepartum haemorrhage & $03(01.8)$ \\
\hline Decreased fetal movements & $01(0.6)$ \\
\hline No risk factors & $06(03.9)$ \\
\hline $\begin{array}{r}\text { Total } \\
\end{array}$ & $152(100)$ \\
\hline
\end{tabular}

The distribution of organ system involvement is shown in Table 4. The distribution of organ dysfunction and outcome is shown in Figure 1. The relationship between the numbers of dysfunctional organs and outcome is shown in Figure 2.

Table 4: Distribution of organ system involvement

\begin{tabular}{|l|c|c|}
\hline \multicolumn{1}{|c|}{ Organ involved } & Number of cases involved (\%) & Number of cases not involved (\%) \\
\hline Renal system & $98(64)$ & $54(36)$ \\
\hline Respiratory system & $68(45)$ & $84(55)$ \\
\hline Cardiovascular system & $48(32)$ & $104(68)$ \\
\hline Gastrointestinal system & $24(16)$ & $128(84)$ \\
\hline Metabolic system & $16(10)$ & $136(90)$ \\
\hline Hepatic system & $07(05)$ & $145(95)$ \\
\hline Haematological system & $05(03)$ & $147(97)$ \\
\hline
\end{tabular}

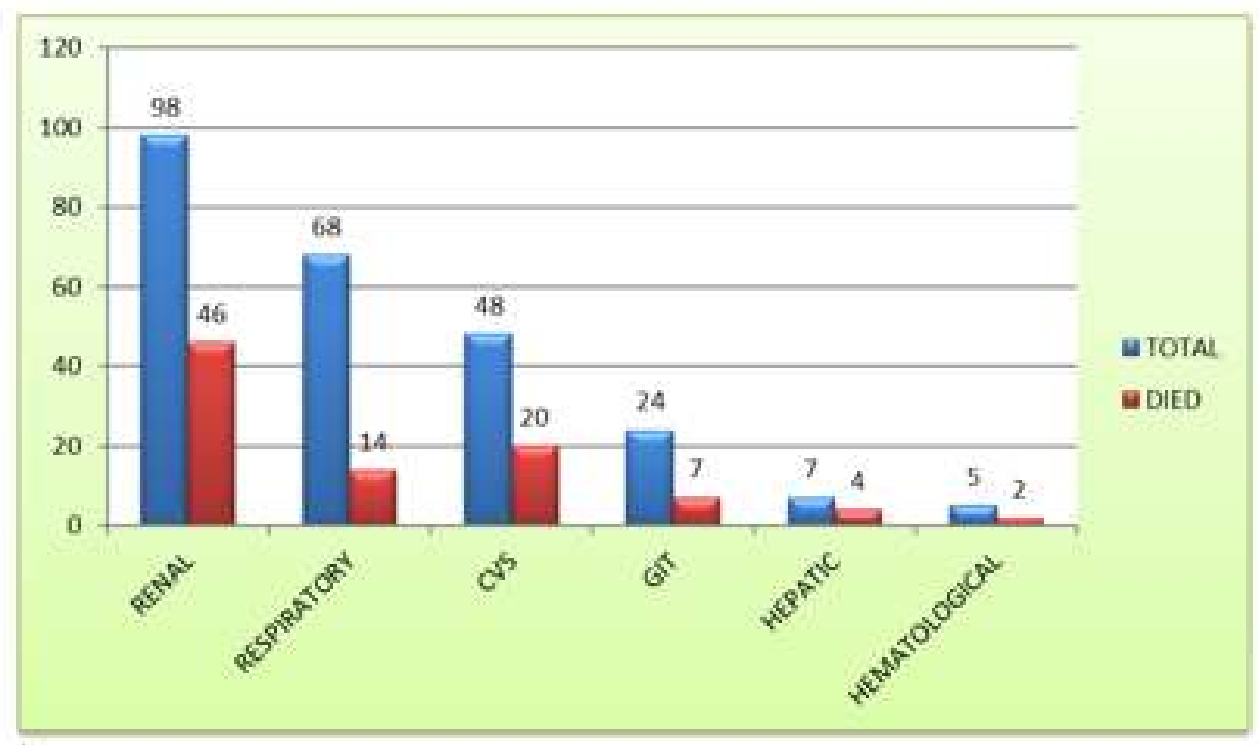

Figure 1: Distribution of organ dysfunction and outcome 


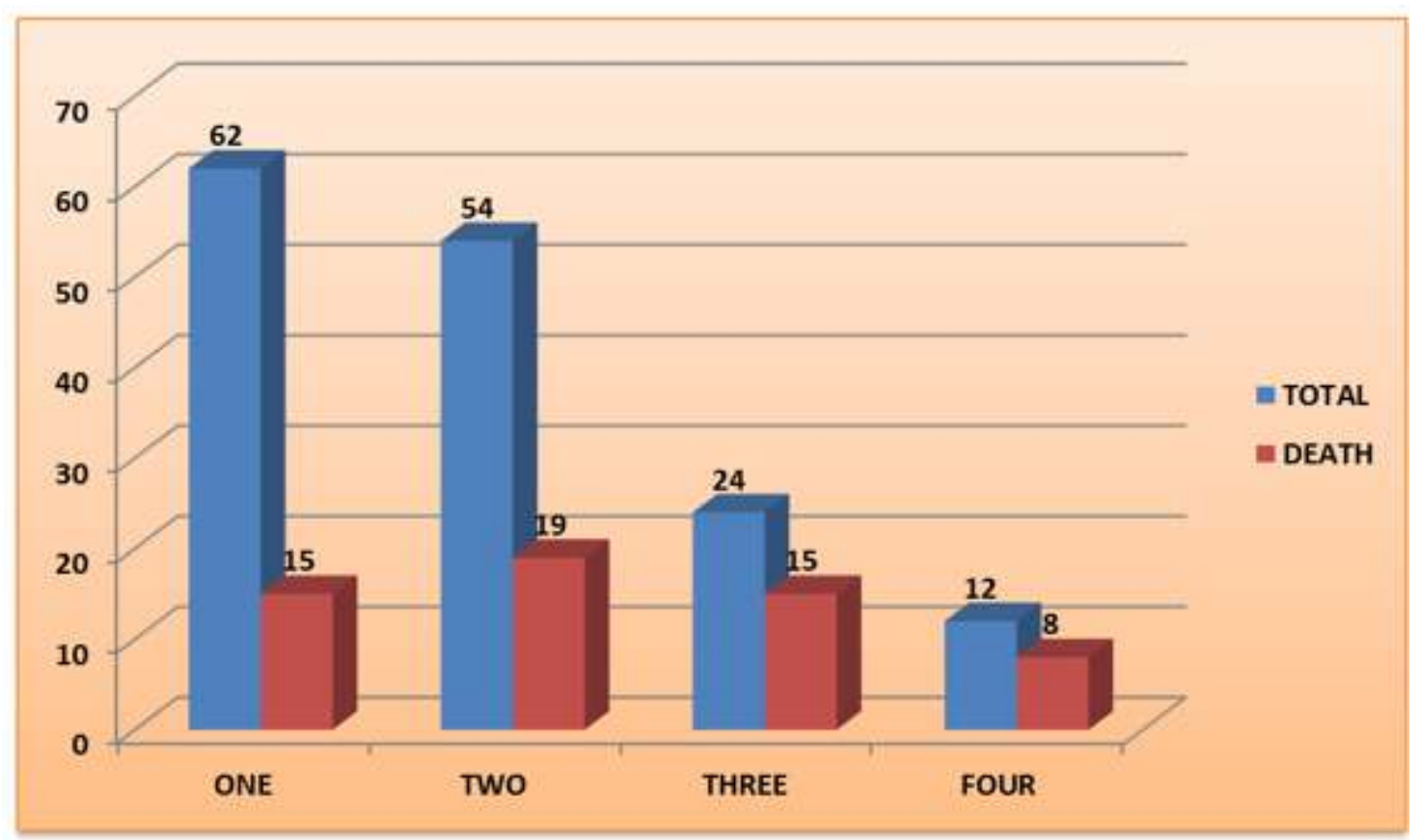

Figure 2: Relationship between the number of dysfunctional organs and outcome

Out of a total of 152 babies studied, 95 survived to hospital discharge and $57(37 \%)$ died. The relationship between organ dysfunction and outcome is shown in Figure 1.

\section{Discussion}

The study was undertaken to observe the effects of birth asphyxia on various organ systems of the neonate other than the CNS. One hundred fifty two asphyxiated neonates were followed up for 14 days to note the involvement of the renal system, respiratory system, cardiovascular system, gastrointestinal system, hepatic system, haematological system and the metabolic system.

In the present study, 96\% neonates had risk factors for perinatal asphyxia in various forms (Table 3). Ross MG considered the presence of meconiumstained amniotic fluid strong evidence of fetal distress $^{2}$. Shrestha $\mathrm{M}$ et al. studied the risk factors of hypoxic ischaemic encephalopathy (HIE) and showed that meconium staining of the amniotic fluid was the commonest risk factor $(65 \%)^{3}$. In our study, meconium stained amniotic fluid (35.5\%) was the most common risk factor in perinatal asphyxia. Bhargava SK et al has documented cord prolapse $(50 \%)$, malpresentation $(32 \%)$ and fetal distress $(26.6 \%)$ as major risk factors in perinatal asphyxia ${ }^{4}$. In our study cord prolapse occurred in $07.7 \%$ and malpresentation in $0.5 \%$.

In the present study the most commonly affected organ system was the renal system $(64 \%)$ followed by the respiratory system $(45 \%)$, the cardiovascular system $(32 \%)$, the gastrointestinal system $(16 \%)$, the hepatic system $(05 \%)$ and the haematological system $(03 \%)$. In the study by Shah $\mathrm{P}$ et al. the renal system was involved in $70 \%$, the respiratory system in $86 \%$ and the cardiovascular system in $62 \% 5$. In the study by Martin-Ancel $\mathrm{A}$, et al. the renal system was involved in $42 \%$, the respiratory system in $26 \%$, the cardiovascular system in $29 \%$ and the gastrointestinal system in $29 \%{ }^{6}$. In the study by Perlman JM et al, the renal system was involved in $40 \%$, the respiratory system in $23 \%$ and the cardiovascular system in $28 \% 7$.

An overall mortality rate of $37.5 \%$ was observed in the present study. In the study by Shah $\mathrm{P}$ et al. $62 \%$ neonates had adverse outcome including death ${ }^{6}$. A $7 \%$ mortality was reported by Goodwin TM, et al ${ }^{8}$.

\section{Conclusions}

In the present study common organs of involvement other than the CNS were renal (64\%), respiratory $(45 \%)$, cardiovascular $(32 \%)$ and gastrointestinal $(16 \%)$. The overall mortality rate was $37.5 \%$. Deaths were higher when 3 or more organs were involved.

\section{References}

1. McIntosh N, Stenson B. Birth asphyxia. In Forfar and Arneil Textbook of Paediatrics. 6th edition. New York, USA: Churchill Livingstone; 2003: p. 197-201.

2. Ross MG. Meconium aspiration syndrome: More than intrapartum meconium. The New England Journal of Medicine 2005; 353(9):946-8. 
https://doi.org/10.1056/NEJMe058149

PMid: 16135842

3. Shrestha M, Shrestha L, Shrestha PS. Profile of asphyxiated babies at Tribhuvan University Teaching Hospital. Journal of Nepal. Paediatric Society 2009; 29(1): 35.

4. Bhargava SK, Batra A, Sen Gupta A, Das SK. A study of asphyxia neonatorum. Journal of Obstetrics and Gynecology of India 1988; 38: 162-6.

5. Shah P, Riphagen S, Beyene J, Perlman M. Multiorgan dysfunction in infants with post asphyxial hypoxic ischaemic encephalopathy. Archives of Disease in Childhood Fetal and Neonatal Edition 2004; 89:F152-5.

https://doi.org/10.1136/adc.2002.023093

PMid: 14977901 PMCid: PMC1756028
6. Martin-Ancel A, Garcia-Alix A, Gaya F, Cabanas F, Burqueros M, Quero J. Multiple organ involvement in perinatal asphyxia. Journal of Pediatrics 1995; 127(5): 786-93.

https://doi.org/10.1016/S00223476(95)701 74-5

7. Perlman JM, Tack ED et al. Acute systemic organ injury in term infants after asphyxia. Am J Dis Child. 1989; 43: 617-620.

https://doi.org/10.1097/001325821989100 00-00022

8. Goodwin TM, Belai I, Hernandez P, Durand M, Paul RH. Asphyxial complications in term newborn with severe umbilical acidaemia. American Journal of Obstetrics and Gynecology 1992; 162: $1506-12$. https://doi.org/10.1016/00029378(92)9172 $8-\mathrm{S}$ 